\title{
DESEMPEÑO DE PROGENIES, PROCEDENCIAS Y REGIONES DE PROCEDENCIA DE ROBLE (Nothofagus obliqua (Mirb.) Oerst)
}

\author{
Gutiérrez, Braulio²
}

\section{RESUMEN}

Se analiza el efecto de las progenies, procedencias y regiones de procedencia sobre el desempeño en supervivencia, altura, diámetro, volumen, rectitud y bifurcaciones de fuste en un ensayo de procedencias y progenies de roble (Nothofagus obliqua) de 16 años de edad, establecido en San José de la Mariquina (39³3,167'S; $\left.73^{\circ} 4,356^{\prime} \mathrm{O}\right)$, región de Los Ríos, Chile.

Se detecta escasa diferenciación entre procedencias y regiones de procedencias, y se discute sobre su posible causa. Se presentan los datos descriptivos del ensayo y se calcula la superioridad asociada al uso del material genético local y al de mejor desempeño. Se concluye que los mejores orígenes, y particularmente las mejores progenies, involucran una importante superioridad de volumen respecto a la media del ensayo. Sin embargo, no se observó coincidencia entre los materiales locales y los de mejor desempeño.

Palabras clave: Nothofagus obliqua, progenie, procedencia, crecimiento

\section{SUMMARY}

The effect of progeny, provenance and provenance regions on performance in survival, height, diameter, volume, straightness and stem bifurcations was analyzed in a 16-year-old Nothofagus obliqua provenance and progeny trial. This trial was established in San José de la Mariquina $\left(39^{\circ} 33,167^{\prime} \mathrm{S} ; 73^{\circ} 4,356^{\prime} \mathrm{W}\right)$, Los Ríos region, Chile.

Little differentiation between provenances and provenance regions was detected, and its possible cause is discussed. The descriptive data of the trial are presented; the superiority associated with the use of local genetic material and those with the best performance is calculated. It is concluded that the best origins, and particularly the best progenies, involve an important volume superiority with respect to the test mean. However, no match was observed between local and best performing materials.

Keywords: Nothofagus obliqua, progenies, provenance, growth.

\footnotetext{
${ }^{2}$ Ingeniero Forestal. Instituto Forestal, Sede Bio Bio. bgutierr@infor.cl
} 


\section{INTRODUCCIÓN}

Los ensayos de procedencia-progenie de especies forestales combinan la evaluación del origen del material (procedencia, región de procedencia) con el desempeño de progenies de árboles individuales procedentes de tales orígenes.

En el ámbito del mejoramiento genético estos ensayos tienen una importancia capital: permiten evaluar la adaptabilidad de los materiales en un ambiente determinado; identificar el origen y material genético idóneo para plantación; generar información técnica (parámetros genéticos) para orientar las decisiones del programa de mejoramiento; determinar el valor genético de progenitores selectos en función del desempeño de sus progenies; generar información para establecer y depurar estructuras de producción de semilla mejorada; seleccionar hacia adelante los ejemplares que conformarán las siguientes generaciones de mejora; y orientar respecto a las ganancias genéticas posibles de obtener con el uso de los distintos materiales genéticos ensayados.

La evaluación de los ensayos de procedencia y progenie no solo permite determinar los mejores orígenes, sino que simultáneamente permite seleccionar los mejores individuos dentro de las mejores procedencias (León, 2014; Landa et al., 2002).

Así, la primera aplicación práctica de estos ensayos es la de conocer el desempeño de los distintos materiales ensayados e identificar a los más apropiados para zonas equivalentes a aquella donde el ensayo está establecido. De esta forma, se cuenta con información objetiva que respalde las decisiones respecto al origen del material genético a utilizar para establecer una plantación. Tal aspecto se hace especialmente relevante en un contexto de cambio climático, donde se reconoce que la tradicional y prudente recomendación de preferir semilla de origen local, ha demostrado no ser siempre la opción idónea (Gutiérrez, 2019; Alía et al., 2009).

En efecto, generalmente se considera que la semilla de origen o procedencia local tiene el mayor potencial adaptativo (Mijnsbrugge et al., 2010; McKay et al., 2005), sin embargo, la investigación genética indica que la distancia geográfica es un mal predictor de la diferenciación adaptativa. Esto significa que no hay distancia fija o regla de oro para determinar hasta dónde se pueden mover con éxito las plantas a partir del lugar de origen de sus semillas.

El concepto "local" queda mejor definido por la similitud climática y ambiental del material de origen en relación con el sitio de plantación a donde será transferido (Erikson y Halford, 2020). Por otra parte, existen situaciones en que orígenes foráneos pueden resultar más apropiados, especialmente cuando las poblaciones locales han perdido variabilidad genética y exhiben pérdidas de adaptabilidad que no garantizan su permanencia en el escenario climático proyectado a futuro (Jones y Monaco, 2007; Lowe, 2010).

Al respecto, en el presente documento se evalúa un ensayo de procedencias y progenies de roble, especie que junto a raulí y coigüe, posee un alto potencial productivo y cuyas tasas de crecimiento y propiedades de su madera concitan el mayor interés entre los árboles nativos por utilizarla en plantaciones (Donoso y Soto, 2010).

En efecto, los bosques de roble ha sido uno de los más cosechados en Chile, debido a la accesibilidad de sus bosques y fundamentalmente por el atractivo de su madera, que presenta valiosas propiedades mecánicas y durabilidad que admite diversos usos; adicionalmente roble destaca por una buena poda natural, lo que permite plantarlo a densidades iniciales no muy altas, obteniéndose así madera de mayor calidad (CONAF, 1998 cit por Gutiérrez, 2004). 
El desarrollo de estas plantaciones mejorará en la medida que se utilicen adecuadas técnicas silvícolas y material genético idóneo procedente de los orígenes adecuados para cada sitio de plantación.

En tal sentido, el objetivo de la presente evaluación es conocer la variabilidad de desempeño en términos de supervivencia, altura, diámetro, volumen, rectitud y bifurcaciones del fuste de progenies de roble originarias de 19 procedencias clasificadas en 9 regiones de procedencia, con la finalidad de orientar a propietarios e instituciones interesadas en plantaciones comerciales o de restauración, respecto a los orígenes y materiales genéticos apropiados para mejorar perspectivas de rendimiento, perpetuación y regeneración de los árboles implantados.

\section{MATERIAL Y MÉTODO}

\section{Ensayo y Material Genético}

Se analiza la evaluación a los 16 años de edad del ensayo de procedencias y progenies de roble Huillilemu. Este se ubica en el predio del mismo nombre, perteneciente a la Corporación Nacional Forestal, en la comuna de San José de la Mariquina, región de Los Ríos, $\left(39^{\circ} 33,167^{\prime} S\right.$; $\left.73^{\circ} 4,356^{\prime} \mathrm{O}\right)$.

El ensayo se encuentra a una altitud de $23 \mathrm{msnm}$, en un área de clima templado lluvioso, clasificada dentro del subtipo clima de costa occidental con influencia mediterránea (García et al., 2013). Las características climáticas del área se resumen en el Cuadro $\mathrm{N}^{\circ} 1$.

\section{Cuadro $\mathrm{N}^{\circ} 1$ \\ CARACTERÍSTICAS CLIMÁTICAS DEL AREA DE EMPLAZAMIENTO DEL ENSAYO DE PROCEDENCIAS Y PROGENIES DE ROBLE PUMILLAHUE}

\begin{tabular}{|l|c|}
\hline Variable Climática & Valor \\
\hline $\mathrm{T}^{\circ}$ media estival & $16,0^{\circ} \mathrm{C}$ \\
\hline $\mathrm{T}^{\circ}$ min y max estival & $10,6^{\circ} \mathrm{C} ; 23,0^{\circ} \mathrm{C}$ \\
\hline $\mathrm{T}^{\circ}$ media invernal & $7,4^{\circ} \mathrm{C}$ \\
\hline $\mathrm{T}^{\circ}$ min y max invernal & $4,0^{\circ} \mathrm{C} ; 11,6^{\circ} \mathrm{C}$ \\
\hline $\mathrm{PP}$ normal anual & $1915 \mathrm{~mm}$ \\
\hline
\end{tabular}

(Fuente: MMA, 2016)

El material genético representado en el ensayo corresponde al obtenido en un muestreo genético realizado a fines de los 90, en el marco del proyecto FONDEF D96-I1052 ${ }^{3}$, basado en la definición de regiones de procedencia efectuada por Vergara et al. (1998) para la distribución natural de roble.

\footnotetext{
${ }^{3}$ Proyecto D96 I-1052 "Mejoramiento Genético para Especies de Nothofagus de Interés Económico" ejecutado entre 1997 y 1999 por el Instituto Forestal y la Universidad Austral de Chile.
} 
Esta clasificación contempló criterios climáticos, fitogeográficos, orográficos y topográficos, a partir de los cuales se definió 14 regiones de procedencia para roble (2 de ellas en territorio argentino), abarcando toda la distribución natural de la especie.

El ensayo considera 5 bloques completos al azar donde se prueban 92 progenies de roble, correspondientes a 21 procedencias o puntos de muestreo representativos de 9 de las zonas de procedencia definidas por Vergara et al. (1998), las que se representan en la Figura $N^{\circ} 1$. Las progenies involucradas en este ensayo se representan en cada bloque por una parcela de un árbol.

Las progenies consideradas en la evaluación fueron aquellas que presentaban árboles vivos en al menos 4 de los 5 bloques del ensayo, estas corresponden a 85 progenies de 19 procedencias y 9 regiones de procedencia (Cuadro $\mathrm{N}^{\circ} 2$ ).

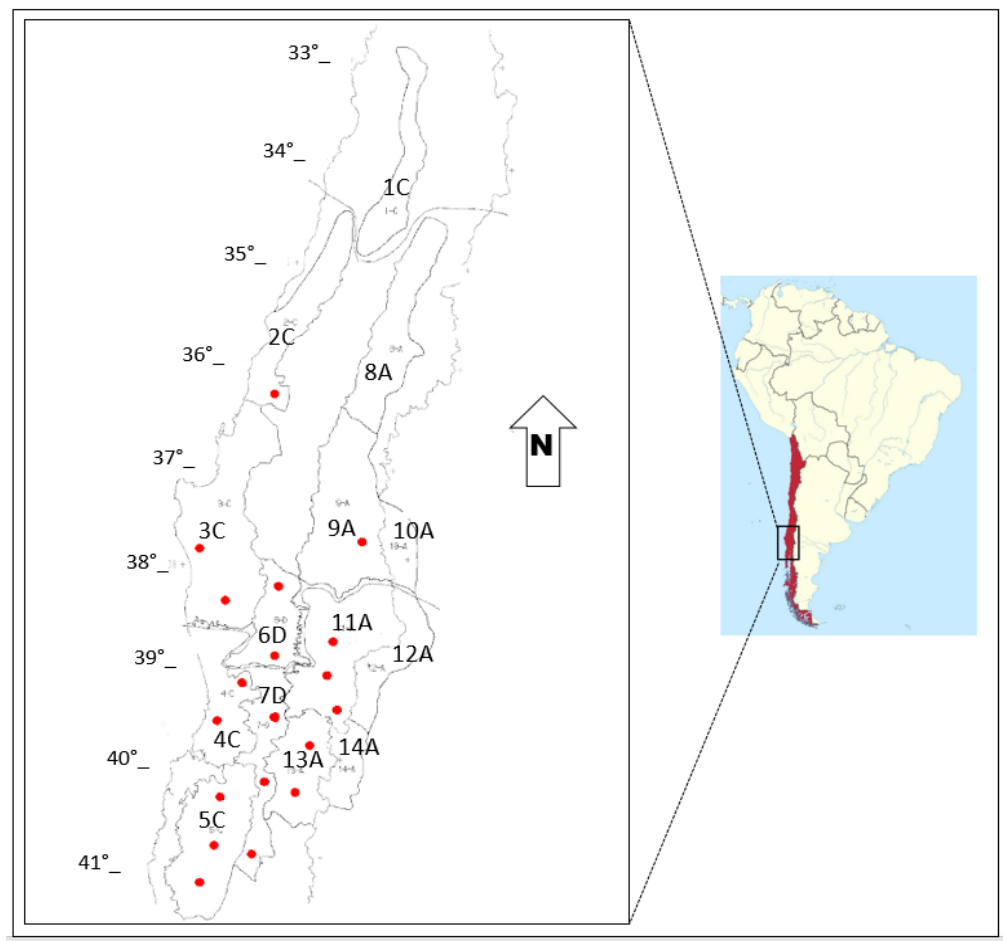

(Fuente: adaptado de Vergara et al., 1998)

Figura $\mathrm{N}^{\circ} 1$

PUNTOS DE MUESTREO Y REGIONES DE PROCEDENCIAS REPRESENTADAS EN ENSAYO DE ROBLE HUILLILEMU 


\section{Cuadro $\mathrm{N}^{\circ} 2$ \\ MATERIAL GENÉTICO EVALUADO EN ENSAYO DE PROCEDENCIAS Y PROGENIES DE ROBLE HUILLILEMU}

\begin{tabular}{|c|c|c|c|c|c|}
\hline $\begin{array}{l}\text { Región de } \\
\text { Procedencia }\end{array}$ & $\begin{array}{l}\text { Procedencia } \\
\text { (Punto de } \\
\text { Muestreo) }\end{array}$ & $\begin{array}{l}\text { Latitud } \\
{ }^{\circ} \mathrm{S}\end{array}$ & $\begin{array}{l}\text { Longitud } \\
{ }^{\circ} W\end{array}$ & $\begin{array}{l}\mathrm{N}^{\circ} \mathrm{de} \\
\text { Progenies }\end{array}$ & $\begin{array}{c}\text { Códigos de Progenies } \\
\text { (rango) }\end{array}$ \\
\hline 2-C & Quirihue & $36^{\circ} 17^{\prime} 53^{\prime \prime}$ & $72^{\circ} 31^{\prime} 54^{\prime \prime}$ & 1 & 259 \\
\hline \multirow[b]{2}{*}{$3-C$} & Pichipillahuén & $38^{\circ} 19^{\prime} 47^{\prime \prime}$ & $72^{\circ} 02^{\prime} 25^{\prime \prime}$ & 5 & $398-403$ \\
\hline & L. Lanalhue & $37^{\circ} 50^{\prime} 50^{\prime \prime}$ & $73^{\circ} 20^{\prime} 52^{\prime \prime}$ & 2 & $378-382$ \\
\hline \multirow{2}{*}{ 4-C } & Cuesta Lastarria & $39^{\circ} 22^{\prime} 30^{\prime \prime}$ & $72^{\circ} 42^{\prime} 21^{\prime \prime}$ & 6 & $448-455$ \\
\hline & Cruces $^{(*)}$ & $39^{\circ} 31^{\prime} 32^{\prime \prime}$ & $73^{\circ} 04^{\prime} 13^{\prime \prime}$ & 7 & $476-485$ \\
\hline \multirow{3}{*}{$5-C$} & Llancacura & $40^{\circ} 17^{\prime} 45^{\prime \prime}$ & $73^{\circ} 26^{\prime} 18^{\prime \prime}$ & 5 & $517-525$ \\
\hline & Rio Negro & $40^{\circ} 47^{\prime} 8^{\prime \prime}$ & $73^{\circ} 16^{\prime} 26^{\prime \prime}$ & 8 & $526-535$ \\
\hline & Purranque & $40^{\circ} 52^{\prime} 02^{\prime \prime}$ & $73^{\circ} 14^{\prime} 09^{\prime \prime}$ & 8 & $546-553$ \\
\hline \multirow{2}{*}{ 6-D } & Victoria & $38^{\circ} 12^{\prime} 14^{\prime \prime}$ & $72^{\circ} 10^{\prime} 23^{\prime \prime}$ & 5 & $390-394$ \\
\hline & Quepe & $38^{\circ} 52^{\prime} 2^{\prime \prime}$ & $72^{\circ} 30^{\prime} 24^{\prime \prime}$ & 7 & $426-435$ \\
\hline \multirow{3}{*}{ 7-D } & Malalhue & $39^{\circ} 30^{\prime} 55^{\prime \prime}$ & $72^{\circ} 32^{\prime} 06^{\prime \prime}$ & 5 & $466-475$ \\
\hline & Futrono & $40^{\circ} 04^{\prime} 53^{\prime \prime}$ & $72^{\circ} 20^{\prime} 16^{\prime \prime}$ & 4 & $509-515$ \\
\hline & Rupanco & $40^{\circ} 49^{\prime} 29^{\prime \prime}$ & $72^{\circ} 54^{\prime} 5^{\prime \prime}$ & 2 & $537-541$ \\
\hline 9-A & Ralco & $37^{\circ} 53^{\prime} 11^{\prime \prime}$ & $71^{\circ} 35^{\prime} 11^{\prime \prime}$ & 2 & $367-370$ \\
\hline \multirow{3}{*}{ 11-A } & Cunco & $38^{\circ} 52^{\prime} 02^{\prime \prime}$ & $71^{\circ} 51^{\prime} 11^{\prime \prime}$ & 1 & 424 \\
\hline & L. Colico & $39^{\circ} 01^{\prime} 14^{\prime \prime}$ & $72^{\circ} 0^{\prime} 48^{\prime \prime}$ & 7 & $437-445$ \\
\hline & Curarrehue & $39^{\circ} 22^{\prime} 53^{\prime \prime}$ & $71^{\circ} 32^{\prime} 00^{\prime}$ & 4 & $456-461$ \\
\hline \multirow{2}{*}{ 13-A } & Choshuenco & $39^{\circ} 50^{\prime} 43^{\prime \prime}$ & $72^{\circ} 05^{\prime} 49^{\prime \prime}$ & 1 & 495 \\
\hline & Llifén & $40^{\circ} 11^{\prime} 08^{\prime \prime}$ & $72^{\circ} 15^{\prime} 00^{\prime}$ & 3 & $496-505$ \\
\hline Testigo & $\begin{array}{l}\text { Mezcla de familias de } \\
\text { roble }\end{array}$ & & & 1 & 901 \\
\hline
\end{tabular}

(") La procedencia Cruces se considera local en el lugar de emplazamiento del ensayo.

\section{Variables y Evaluación}

Se evaluó la existencia de diferencias de desempeño entre progenies, procedencia y regiones de procedencias.

Las variables independientes para evaluar el desempeño de los árboles individuales fueron supervivencia (SUP), altura total (ALT), diámetro a la altura del pecho (DAP), volumen (VOL), rectitud de fuste (RF) y Bifurcaciones (BIF).

La supervivencia (SUP) se calculó en porcentaje y consideró como base el total de plantas de todas las progenies establecidas inicialmente en el ensayo; para las variables restantes se consideró solo las progenies con árboles vivos en al menos 4 de los 5 bloques del ensayo.

La rectitud de fuste (RF) se evaluó con una escala cualitativa de cuatro niveles (Figura $\mathrm{N}^{\circ}$ 2); las bifurcaciones (BIF) se estimaron como el porcentaje de árboles con fustes bifurcados en la altura comercial, respecto al número total de árboles en cada categoría de análisis (progenies, procedencias y regiones de procedencia); el volumen utilizado (VOL) corresponde al volumen sólido sin corteza, estimado con la función general desarrollada por Puente et al. (1981) para renovales de roble (Expresión 1).

EI DAP corresponde al diámetro del fuste a 1,3 metros del suelo y la altura (ALT) es el valor total desde el suelo hasta el ápice del árbol. 
Donde:

V: volumen sólido sin corteza $\left[\mathrm{m}^{3}\right]$

D: diámetro $[\mathrm{cm}]$

$\mathrm{H}$ : altura $[\mathrm{m}]$

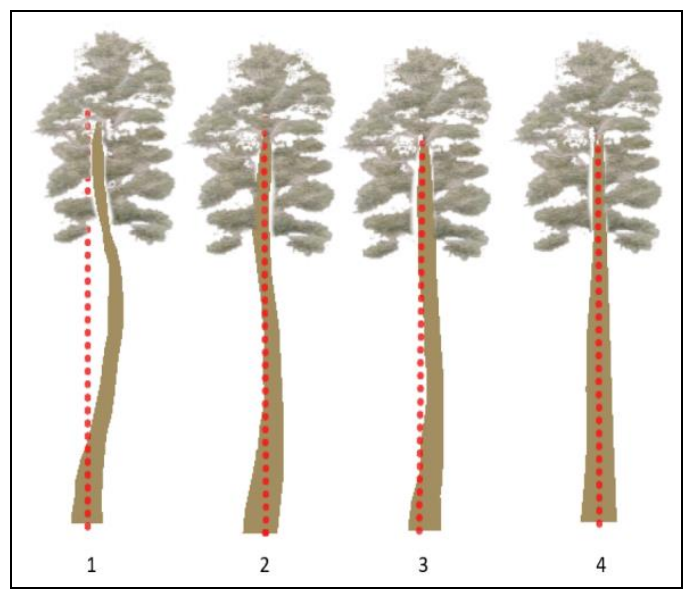

Figura $\mathrm{N}^{\circ} 2$

ESCALA CUALITATIVA PARA EVALUACIÓN DE RECTITUD DE FUSTE

Se calculó los parámetros medios y de dispersión del ensayo para cada variable evaluada (SUP, H, DAP, VOL, RF y BIF), y se efectuó análisis de varianza (ANOVA) para verificar la existencia de diferencias estadísticamente significativas para cada una de las variables a nivel progenies, procedencias y regiones de procedencia.

Los análisis de varianza se complementaron con la prueba de Tuckey para comparación múltiple de medias (alfa $=0,05$ ), usando la diferencia mínima significativa (DMS) como criterio para decidir la existencia de diferencias estadísticamente significativas entre medias.

Tanto en los ANDEVA como en las pruebas de Tuckey para cada variable independiente se usó como variables de clasificación a los bloques y a la posición del árbol en el ensayo, representada esta última por las coordenadas $\mathrm{X}$ e $\mathrm{Y}$ de las filas y columnas que definen su ubicación dentro del diseño del mismo.

Para efectos del análisis estadístico, las variables supervivencia y bifurcaciones, ambas expresadas en porcentaje, fueron previamente transformadas a unidades de Bliss, esta transformación conocida también como transformación angular o del arcoseno es especialmente apropiada para variables en porcentajes o proporciones (Sokal y Rohlf, 1980; Mead et al., 2002).

Después del análisis, para efectos de presentación de resultados, los valores medios y las diferencias mínimas significativas fueron revertidos nuevamente a porcentajes. 


\section{RESULTADOS Y DISCUSIÓN}

\section{Caracterización del Ensayo}

La caracterización general del ensayo, en término de promedio, desviación estándar y diferencias mínimas significativas para cada una de las variables evaluadas se resume en el Cuadro $\mathrm{N}^{\circ} 3$. individuales.

En la Figura $\mathrm{N}^{\circ} 3$ se resume las distribuciones de las variables a nivel de árboles

\section{CARACTERIZACIÓN GENERAL DEL ENSAYO DE PROCEDENCIAS Y PROGENIES DE ROBLE HUILLILEMU}

\begin{tabular}{|c|r|r|r|r|r|r|}
\hline \multirow{2}{*}{ Descriptor } & \multicolumn{6}{|c|}{ Variables } \\
\cline { 2 - 7 } & $\begin{array}{c}\text { SUP } \\
{[\%]}\end{array}$ & $\begin{array}{c}\text { ALT } \\
{[\mathbf{m}]}\end{array}$ & $\begin{array}{c}\text { DAP } \\
{[\mathbf{c m}]}\end{array}$ & $\begin{array}{c}\text { VOL } \\
{\left[\mathbf{m}^{3}\right]}\end{array}$ & $\begin{array}{c}\text { RF } \\
{[1-4]}\end{array}$ & $\begin{array}{r}\text { BIF } \\
{[\%]}\end{array}$ \\
\hline $\mathbf{n}$ & 540 & 470 & 470 & 470 & 470 & 470 \\
\hline Promedio & 90,52 & 12,37 & 14,25 & 0,14 & 2,57 & 14,95 \\
\hline Desviación Estándar & 28,05 & 1,72 & 3,25 & 0,04 & 0,72 & 34,26 \\
\hline Valor mínimo & 0 & 4,2 & 4,3 & 0,05 & 1 & 0 \\
\hline Valor máximo & 100 & 16,7 & 25,1 & 0,38 & 4 & 100 \\
\hline
\end{tabular}

Los resultados de los análisis estadísticos de varianza y pruebas de comparación múltiple de medias (Tuckey) no experimentaron cambios como consecuencia de usar, como variables de clasificación complementaria a los bloques, a las coordenadas de posición XY de los árboles en el ensayo.

El terreno del ensayo resulta suficientemente homogéneo de modo que tanto las columnas como las filas no tienen efectos significativos.

En teoría, considerar estas fuentes de variación adicional permite separar de mejor forma las sumas de cuadrados y disminuir el cuadrado medio residual, permitiendo mejorar la precisión de las dócimas asociadas a las principales fuentes de variación en análisis (progenies, procedencias, regiones de procedencia).

No obstante, en la práctica tal mejora no resultó significativa ni modificó las conclusiones de las pruebas efectuadas sin considerar las coordenadas $X Y$. 


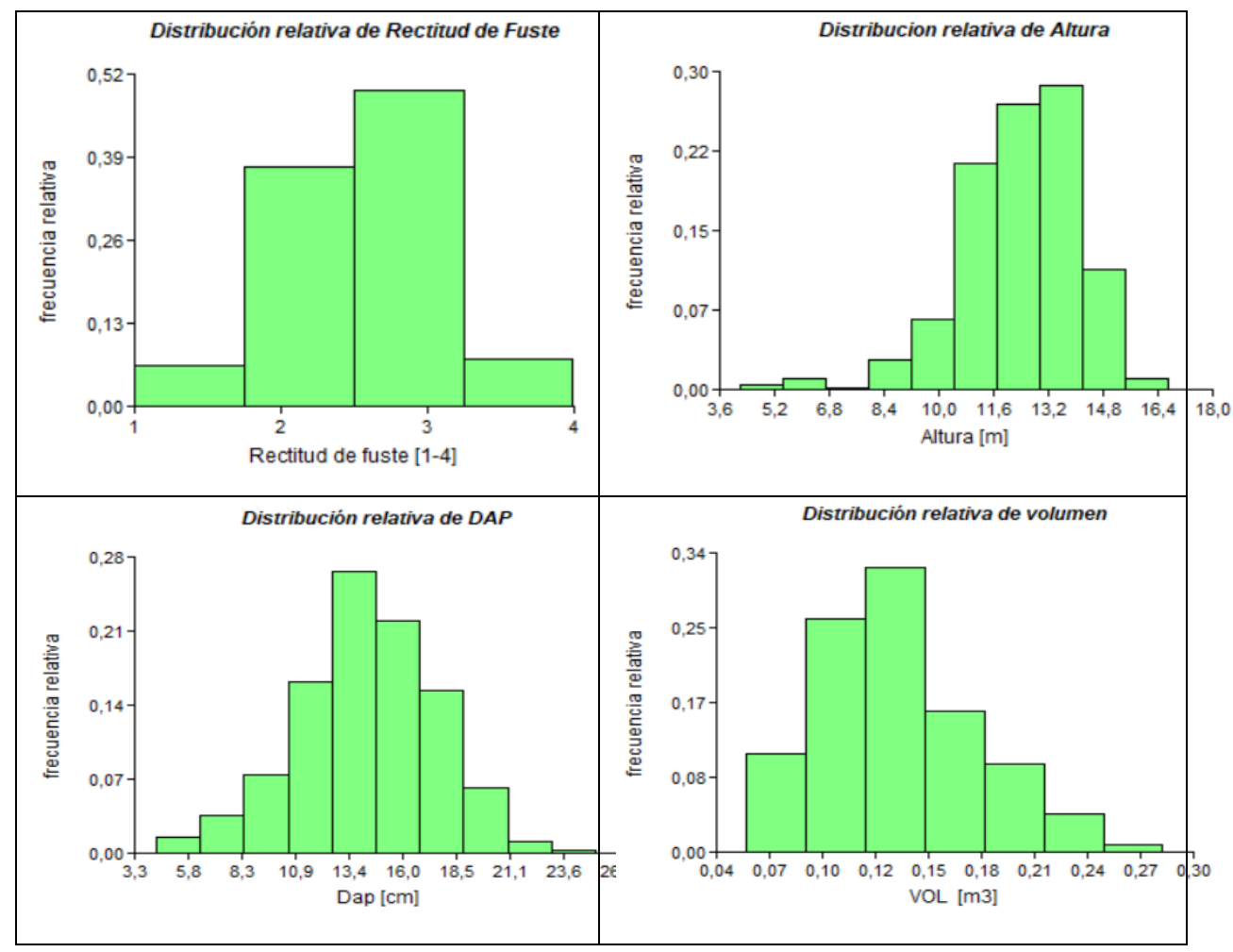

Figura $\mathrm{N}^{\circ} 3$

DISTRIBUCIÓN DE FRECUENCIA RELATIVA DE RECTITUD DE FUSTE, ALTURA, DAP Y VOLUMEN EN LOS ÁRBOLES DEL ENSAYO DE PROCEDENCIAS Y PROGENIES DE ROBLE HUILLILEMU

En cuanto a las variables estudiadas, la supervivencia a los 16 años de las plantas de roble ensayadas en Huillilemu $(90,52 \%)$, es alta y equivalente a la señalada por Donoso y Soto (2010) para plantaciones de solo siete años en la zona de Panguipulli $(90,6 \%)$.

La rectitud de fuste $(2,57)$, aun cuando no se dispone de datos referenciales en la misma especie para compararla, parece relativamente alta y resulta considerablemente mejor que la observada en plantaciones de coigüe de similar edad, las que alcanzan valores de 1,4 en el mismo sitio del ensayo evaluado en Huillilemu, y 1,7 en un ensayo establecido en Neltume (Gutiérrez, 2020).

En cuanto a la incidencia de bifurcaciones, en el ensayo de roble estas corresponden a menos del $15 \%$ de los individuos evaluados; como referencia, en una plantación de coigüe de similar edad en el mismo sitio, se determinó un porcentaje de individuos bifurcados que llega al 47,8\% (Gutiérrez, 2017). 
Respecto al crecimiento del ensayo, los valores medios de altura $(12,37 \mathrm{~m})$ y DAP $(14,25$ $\mathrm{cm}$ ) registrados en Huillilemu, a los 16 años de edad, corresponden a incrementos medios anuales

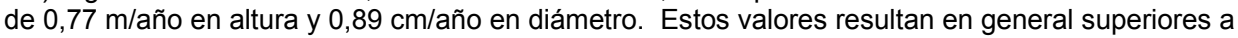
los señalados para otras plantaciones de roble, siendo mayor la diferencia en diámetro que en altura. Las diferencias se hacen más evidentes al contrastar el desempeño de las mejores progenies y procedencia de Huillilemu respecto a las plantaciones de comparación (Cuadro $\mathrm{N}^{\circ} 4$ ).

\section{Cuadro $\mathrm{N}^{\circ} 4$ \\ INCREMENTOS MEDIOS ANUALES DE ALTURA Y DIÁMETRO EN PLANTACIONE DE ROBLE Y EN ENSAYO HUILLILEMU}

\begin{tabular}{|c|c|c|c|}
\hline $\begin{array}{c}\text { IMA Altura } \\
\text { [m/año] }\end{array}$ & $\begin{array}{l}\text { IMA DAP } \\
\text { [cm/año] }\end{array}$ & Observacion & Fuente \\
\hline 0,90 & 1,21 & Huillilemu (Mejor Progenie) & \multirow{7}{*}{ Este trabajo } \\
\hline 0,82 & 0,99 & Huillilemu (Mejor Procedencia) & \\
\hline 0,81 & 0,95 & Huillilemu (Mejor Reg de proc) & \\
\hline 0,77 & 0,89 & Huillilemu (Promedio) & \\
\hline 0,70 & 0,69 & Huillilemu (Peor Reg de proc) & \\
\hline 0,70 & 0,69 & Huillilemu (Peor Procedenca) & \\
\hline 0,65 & 0,55 & Huillilemu (Peor Progenie) & \\
\hline $0,50-0,62$ & 0,40 & Llanquihue & Vita, 1977 \\
\hline 0,76 & 0,67 & Llanquihue & Meneses et al., 1991 \\
\hline 0,73 & 0,79 & Chiloé & Meneses et al., 1991 \\
\hline $0,50-0,51$ & $0,50-0,70$ & Frutillar & Gutiérrez, 2004 \\
\hline 0,63 & 0,69 & Riñihue & Donoso et al., 1995 \\
\hline
\end{tabular}

A su vez, los crecimientos registrados en plantaciones resultan superiores a los obtenidos en renovales de bosques naturales de la especie (Steuer, 2008), apoyando así diversas declaraciones respecto a la potencialidad de roble y otros Nothofagus (raulí, coigüe), entre las especies nativas, para utilizarlos en el establecimiento de plantaciones comerciales.

En efecto, de acuerdo con la compilación efectuada por Löewe et al. (1997) el crecimiento diametral de roble en rodales naturales es muy variable $(0,1$ a $1,3 \mathrm{~cm} / \mathrm{año})$, siendo lo más frecuente valores entre 0,3 y $0,4 \mathrm{~cm} / a n ̃ o$ y considerándose como buen crecimiento a valores mayores a 0,5 cm/año (Castillo, 1992, cit. por Löewe et al., 1997).

En términos de volumen, los árboles del ensayo totalizan un valor de $68,5 \mathrm{~m}^{3}$, lo que equivale a $154,5 \mathrm{~m}^{3} /$ ha y a un crecimiento medio anual de $9,7 \mathrm{~m}^{3} / \mathrm{ha} / a n ̃ o$. Según Gutiérrez (2004) para roble y raulí en general se esperan crecimientos en torno a $10 \mathrm{~m}^{3} /$ ha/año.

Löewe et al. (1998, cit por Steuer, 2008) aportan antecedentes sobre el crecimiento en renovales sin manejo, donde el crecimiento se estima en $7 \mathrm{~m}^{3} / \mathrm{ha} / \mathrm{año}$; mientras que en rodales raleados el incremento medio en volumen fue de entre 11 y $12 \mathrm{~m}^{3} / \mathrm{ha} / \mathrm{año}$. 
Donoso et al. (1993 cit. por Gutiérrez, 2004) mencionan valores de entre 10 y 12 $\mathrm{m}^{3}$ /ha/año para plantaciones mixtas con roble y raulí y crecimiento anual medio de $13 \mathrm{~m}^{3} /$ ha/año para plantaciones de roble puro.

Complementariamente, Grosse (1989, cit por Gutiérrez, 2004) menciona una tasa de incremento volumétrico de $10,3 \mathrm{~m}^{3} / \mathrm{ha} /$ año en renoval de roble de 30 años en la zona de Neltume.

\section{Variabilidad}

En general el ensayo no evidencia una diferenciación considerable en el desempeño de roble de distintas progenies, procedencias y regiones de procedencia.

Si bien para algunas variables se detectan diferencias que poseen significación estadística, estas se producen entre las entidades de desempeño extremo (la mejor y la peor) en tanto que las intermedias tienden a ser estadísticamente homogéneas.

En los Cuadros $\mathrm{N}^{\circ} 5$ y $\mathrm{N}^{\circ} 6$ se resume los resultados a nivel de regiones de procedencia y procedencias, respectivamente, para todas las variables analizadas, en ellos se representa también la significancia estadística de las pruebas de comparación múltiple de medias.

Los resultados equivalentes a nivel de progenies, por la extensión del cuadro, se incluyen en el Anexo $\mathrm{N}^{\circ} 1$.

Cuadro $\mathrm{N}^{\circ} 5$

RESULTADOS POR REGIÓN DE PROCEDENCIA

\begin{tabular}{|l|c|c|c|c|c|c|c|c|}
\hline REG PROC & $\mathbf{N}^{*}$ & $\begin{array}{c}\text { SUP } \\
{[\%]}\end{array}$ & $\mathbf{n}^{+}$ & $\begin{array}{c}\text { VOL } \\
{\left[\mathbf{m}^{3}\right]}\end{array}$ & $\begin{array}{c}\text { ALT } \\
{[\mathbf{m}]}\end{array}$ & $\begin{array}{c}\text { DAP } \\
{[\mathbf{c m}]}\end{array}$ & $\begin{array}{c}\text { RF } \\
{[1-4]}\end{array}$ & $\begin{array}{c}\text { BIF } \\
{[\%]}\end{array}$ \\
\hline 7-D & 55 & $94,5 \mathrm{a}$ & 52 & $0,15 \mathrm{a}$ & $12,95 \mathrm{a}$ & $15,20 \mathrm{a}$ & $2,70 \mathrm{a}$ & $13,55 \mathrm{a}$ \\
\hline $6-\mathrm{D}$ & 68 & $98,5 \mathrm{a}$ & 67 & $0,15 \mathrm{a}$ & $12,46 \mathrm{a}$ & $14,75 \mathrm{ab}$ & $2,45 \mathrm{a}$ & $14,38 \mathrm{a}$ \\
\hline $13-\mathrm{A}$ & 20 & $90,0 \mathrm{a}$ & 18 & $0,14 \mathrm{ab}$ & $12,71 \mathrm{a}$ & $13,95 \mathrm{abc}$ & $2,80 \mathrm{a}$ & $5,48 \mathrm{a}$ \\
\hline 4-C [LOCAL] & 75 & $93,3 \mathrm{a}$ & 70 & $0,14 \mathrm{ab}$ & $12,41 \mathrm{a}$ & $14,84 \mathrm{ab}$ & $2,65 \mathrm{a}$ & $22,18 \mathrm{a}$ \\
\hline $11-\mathrm{A}$ & 65 & $96,9 \mathrm{a}$ & 61 & $0,14 \mathrm{ab}$ & $12,36 \mathrm{a}$ & $14,80 \mathrm{ab}$ & $2,38 \mathrm{a}$ & $16,46 \mathrm{a}$ \\
\hline 5-C & 135 & $91,9 \mathrm{a}$ & 124 & $0,13 \mathrm{ab}$ & $12,41 \mathrm{a}$ & $13,82 \mathrm{abc}$ & $2,56 \mathrm{a}$ & $14,61 \mathrm{a}$ \\
\hline TESTIGO & 25 & $92,0 \mathrm{a}$ & 23 & $0,12 \mathrm{ab}$ & $11,92 \mathrm{a}$ & $13,46 \mathrm{abc}$ & $2,60 \mathrm{a}$ & $13,04 \mathrm{a}$ \\
\hline $3-\mathrm{C}$ & 66 & $78,8 \mathrm{a}$ & 42 & $0,12 \mathrm{ab}$ & $11,65 \mathrm{a}$ & $13,12 \mathrm{abc}$ & $2,83 \mathrm{a}$ & $9,00 \mathrm{a}$ \\
\hline 2-C & 6 & $83,3 \mathrm{a}$ & 4 & $0,10 \mathrm{~b}$ & $12,45 \mathrm{a}$ & $11,10 \mathrm{c}$ & $2,25 \mathrm{a}$ & $25,00 \mathrm{a}$ \\
\hline 9-A & 25 & $72,0 \mathrm{a}$ & 9 & $0,10 \mathrm{~b}$ & $11,27 \mathrm{a}$ & $11,63 \mathrm{bc}$ & $2,24 \mathrm{a}$ & $10,92 \mathrm{a}$ \\
\hline PROMEDIO & & 90,5 & & $\mathbf{0}, 14$ & 12,37 & 14,25 & 2,57 & 14,95 \\
\hline DMS & & 23,541 & & 0,047 & 1,786 & 3,369 & 0,742 & 36,632 \\
\hline
\end{tabular}

Letras distintas en la misma columna indican diferencias estadísticamente significativas entre medias (Tuckey alfa $=0,05)$

${ }^{*} \mathrm{~N}$ : Total de plantas iniciales en el ensayo

$+n$ : plantas evaluadas (aquellas de progenies con 4 o más plantas vivas) 
Cuadro $\mathrm{N}^{\circ} 6$

RESULTADOS POR PROCEDENCIA

\begin{tabular}{|c|c|c|c|c|c|c|c|c|}
\hline PROCEDENCIA & $\mathbf{N}^{*}$ & $\begin{array}{l}\text { SUP } \\
\text { [\%] }\end{array}$ & $\mathbf{N}^{+}$ & $\begin{array}{l}\text { VOL } \\
{\left[\mathrm{m}^{3}\right]}\end{array}$ & $\begin{array}{l}\text { ALT } \\
{[\mathrm{m}]}\end{array}$ & $\begin{array}{l}\text { DAP } \\
{[\mathrm{cm}]}\end{array}$ & $\begin{array}{c}\text { RF } \\
{[1-4]}\end{array}$ & $\begin{array}{l}\text { BIF } \\
\text { [\%] }\end{array}$ \\
\hline FUTRONO & 20 & $90,0 a b$ & 18 & $0,16 \mathrm{a}$ & $12,97 \mathrm{a}$ & $15,76 \mathrm{a}$ & $2,39 \mathrm{a}$ & $5,88 \mathrm{a}$ \\
\hline QUEPE & 40 & $100,0 \mathrm{a}$ & 40 & $0,16 \mathrm{a}$ & $12,86 \mathrm{a}$ & $15,61 \mathrm{a}$ & $2,50 \mathrm{a}$ & $20,00 \mathrm{a}$ \\
\hline MALALHUE & 25 & $96,0 a b$ & 24 & 0,15 a & $13,08 \mathrm{a}$ & $15,30 a b$ & $2,97 \mathrm{a}$ & $16,59 \mathrm{a}$ \\
\hline CUESTA LASTARRIA & 35 & $94,3 \mathrm{ab}$ & 33 & 0,15 a & $12,86 \mathrm{a}$ & $15,03 a b$ & $2,59 \mathrm{a}$ & $19,58 \mathrm{a}$ \\
\hline CURARREHUE & 20 & $95,0 \mathrm{ab}$ & 19 & $0,15 \mathrm{a}$ & $12,52 \mathrm{a}$ & $15,36 \mathrm{ab}$ & $2,47 \mathrm{a}$ & $10,66 \mathrm{a}$ \\
\hline COLICO & 40 & $100,0 \mathrm{a}$ & 38 & $0,14 a$ & $12,33 \mathrm{a}$ & $14,45 a b$ & $2,30 \mathrm{a}$ & $18,57 \mathrm{a}$ \\
\hline CHOSHUENCO & 5 & $100,0 \mathrm{a}$ & 5 & $0,14 a$ & $12,24 a$ & $14,76 a b$ & $2,80 \mathrm{a}$ & $0,00 \mathrm{a}$ \\
\hline CRUCES [LOCAL] & 40 & $92,5 a b$ & 37 & $0,14 \mathrm{a}$ & $12,00 \mathrm{a}$ & $14,66 \mathrm{ab}$ & $2,70 \mathrm{a}$ & $24,36 \mathrm{a}$ \\
\hline CUNCO & 5 & $80,0 a b$ & 4 & $0,14 \mathrm{a}$ & $11,95 \mathrm{a}$ & $15,53 \mathrm{a}$ & $2,75 \mathrm{a}$ & $25,00 \mathrm{a}$ \\
\hline LLIFÉN & 15 & $86,7 a b$ & 13 & $0,13 \mathrm{a}$ & $12,89 \mathrm{a}$ & $13,63 a b$ & $2,80 \mathrm{a}$ & $7,56 \mathrm{a}$ \\
\hline PURRANQUE & 40 & $95,0 a b$ & 38 & $0,13 a$ & $12,67 \mathrm{a}$ & $13,99 a b$ & $2,55 \mathrm{a}$ & $20,88 \mathrm{a}$ \\
\hline RUPANCO & 10 & $100,0 \mathrm{a}$ & 10 & $0,13 a$ & $12,60 \mathrm{a}$ & $13,96 a b$ & $2,60 \mathrm{a}$ & $20,00 \mathrm{a}$ \\
\hline RIO NEGRO & 60 & $88,3 a b$ & 53 & $0,13 \mathrm{a}$ & $12,34 \mathrm{a}$ & $13,83 a b$ & $2,48 \mathrm{a}$ & $6,66 \mathrm{a}$ \\
\hline LLANCACURA & 35 & $94,3 \mathrm{ab}$ & 33 & $0,13 \mathrm{a}$ & $12,21 \mathrm{a}$ & $13,58 a b$ & $2,70 \mathrm{a}$ & $16,90 \mathrm{a}$ \\
\hline VICTORIA & 28 & $96,4 \mathrm{ab}$ & 27 & $0,13 \mathrm{a}$ & $11,86 \mathrm{a}$ & $13,47 \mathrm{ab}$ & $2,38 \mathrm{a}$ & $6,18 \mathrm{a}$ \\
\hline LANALHUE & 35 & $62,9 a b$ & 12 & $0,13 \mathrm{a}$ & $11,69 a$ & $13,22 a b$ & $2,91 \mathrm{a}$ & $0,00 \mathrm{a}$ \\
\hline TESTIGO & 25 & $92,0 a b$ & 23 & $0,12 \mathrm{a}$ & $11,92 \mathrm{a}$ & $13,46 a b$ & $2,60 \mathrm{a}$ & $13,00 \mathrm{a}$ \\
\hline PICHIPILLAHUEN & 31 & $96,8 a b$ & 30 & $0,12 \mathrm{a}$ & $11,63 \mathrm{a}$ & $13,08 \mathrm{ab}$ & $2,80 \mathrm{a}$ & $12,74 \mathrm{a}$ \\
\hline QUIRIHUE & 6 & $83,3 a b$ & 4 & $0,10 \mathrm{a}$ & $12,45 \mathrm{a}$ & $11,10 \mathrm{~b}$ & $2,25 \mathrm{a}$ & $25,00 \mathrm{a}$ \\
\hline RALCO & 15 & $80,0 \mathrm{ab}$ & 9 & $0,10 \mathrm{a}$ & $11,27 \mathrm{a}$ & $11,63 a b$ & $2,24 \mathrm{a}$ & $10,91 \mathrm{a}$ \\
\hline RECINTO & 5 & $60,0 \mathrm{~b}$ & \multicolumn{6}{|c|}{ No evaluada } \\
\hline SANTA BÁRBARA & 5 & $60,0 \mathrm{~b}$ & \multicolumn{6}{|c|}{ No evaluada } \\
\hline PROMEDIO & & 90,5 & & 0,14 & 12,37 & 14,25 & 2,57 & 14,95 \\
\hline DMS & & 39,401 & & 0,062 & 2,33 & 4,402 & 0,968 & 50,903 \\
\hline
\end{tabular}

Letras distintas en la misma columna indican diferencias estadísticamente significativas entre medias (Tuckey alfa $=0,05$ )

${ }^{*} \mathrm{~N}$ : Número total de plantas establecidas en el ensayo

$+n$ : Número de plantas evaluadas (aquellas de progenies con 4 o más plantas vivas)

Particularmente las variables rectitud de fuste y porcentaje de bifurcaciones, aun cuando experimentan variabilidad, esta no es estadísticamente significativa a nivel de progenies, procedencias ni regiones de procedencia. Predominan individuos de categorías intermedias de rectitud (Figura $\mathrm{N}^{\circ} 3$ ), no obstante, existen individuos rectos y familias que en promedio alcanzan destacados valores medios de 3,25 y 3,4 en la escala de rectitud; a nivel de procedencias y regiones de procedencia los valores medios son todos inferiores a tres.

La falta de diferenciación entre progenies y orígenes es coincidente con la observada en la evaluación de un ensayo de coigüe de similar edad (Gutiérrez, 2017) donde si bien la calidad de los fustes resultó muy inferior a la de roble, tampoco se evidenció diferencias entre familias, procedencias ni zonas de procedencia. En el caso de coigüe se concluía y respaldaba que las características del fuste serían una característica intrínseca de la especie y que por lo mismo no varía significativamente entre sus distintos orígenes; presumiblemente en roble ocurriría una situación similar. 
En cuanto a supervivencia se detectan diferencias significativas entre procedencias, no obstante, solo las dos procedencias de menor valor (Recinto y Santa Bárbara, $60 \%$ cada una) no forman parte del grupo que reúne a las procedencias de mejor desempeño (80 a 100\%); tampoco presentaban suficientes plantas vivas para ser consideradas en el análisis de las demás variables. La misma situación se observa a nivel de progenies, donde exceptuando a la familia 380 de Lanalhue, con el peor desempeño en supervivencia (20\%), todas las restantes pueden conformar un mismo grupo homogéneo (Anexo 1). Entre regiones de procedencia no se evidencian diferencias para la variable supervivencia.

Respecto a las variables de crecimiento, la altura tiene un desarrollo muy homogéneo y no presenta diferencias de relevancia estadística entre los valores medios de progenies $(11,0$ a $14,4 \mathrm{~m})$, procedencias $(11,3$ a 13,1 $\mathrm{m}$ ) ni regiones de procedencia $(11,3$ a 13,0 m). Se observa una mayor diferenciación para el diámetro y, consecuentemente para el volumen, el cual está estrechamente relacionado con esta variable.

En términos de DAP y volumen destacan los mayores valores de las familias 509 y 433 de las procedencias Futrono y Quepe, en las regiones de procedencia de la depresión intermedia 7D y $6 \mathrm{D}$, respectivamente. A nivel de procedencias, Futrono (7D), Quepe (6D) y Cunco (11A) presentan los mejores desarrollos en diámetro, no obstante, a este nivel las diferencias no resultan significativas para la variable volumen. Por último, con el mayor grado de agregación de la información, se observa que los mejores resultados en DAP corresponden a las regiones de procedencia 7D, 4C, 11A y 6D que cubren los tres estratos fisiográficos del país (depresión intermedia, costa y andes), aun así, en términos de volumen se destacan principalmente las regiones de procedencia 7D y 6D de la depresión intermedia.

El crecimiento de las mejores progenies, procedencias y regiones de procedencia, expresada como porcentaje de superioridad sobre el volumen promedio por árbol individual del ensayo, se resume en el Cuadro $\mathrm{N}^{\circ} 7$. En este se incorpora también el porcentaje de superioridad del las progenies y orígenes locales (progenies de la procedencia Cruces en la región de procedencia $4 \mathrm{C})$.

\section{Cuadro $\mathrm{N}^{\circ} 7$}

SUPERIORIDAD DE LOS MEJORES MATERIALES Y DE LOS MATERIALES LOCALES RESPECTO AL CRECIMIENTO MEDIO EN VOLUMEN DE ROBLE EN ENSAYO PUMILLAHUE A LOS 16 AÑOS DE EDAD

\begin{tabular}{|c|c|c|c|c|}
\hline & & 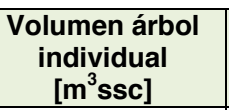 & $\begin{array}{c}\text { Superioridad } \\
{[\%]}\end{array}$ & $\begin{array}{c}\text { Volumen } \\
{\left[\mathrm{m}^{3} / \mathrm{ha}\right]}\end{array}$ \\
\hline \multicolumn{2}{|c|}{ Promedio ensayo } & 0,1364 & 0,00 & 154,5 \\
\hline \multirow{2}{*}{$\begin{array}{l}\text { Regiones de } \\
\text { Procedencia }\end{array}$} & Local (4C) & 0,1425 & 4,47 & 161,4 \\
\hline & Mejores (7D y 6D) & 0,1485 & 8,87 & 168,2 \\
\hline \multirow{2}{*}{ Procedencias } & Local (Cruces) & 0,1385 & 1,54 & 156,9 \\
\hline & Mejores (Futrono y Quepe) & 0,1577 & 15,62 & 178,6 \\
\hline \multirow{2}{*}{ Progenies } & Locales (476 a 485) & 0,1385 & 1,54 & 156,9 \\
\hline & Mejores (509 y 433) & 0,2144 & 57,18 & 242,9 \\
\hline
\end{tabular}

Del cuadro se destaca la progresión de superioridad asociada al uso de las mejores regiones de procedencia $(8,87 \%)$, procedencias $(15,62 \%)$ y progenies $(57,18 \%)$. También resulta evidente que estos valores son muy superiores, en todos los niveles, que los obtenidos con el uso 
de material local, el cual no sobrepasa de 1,5 a $4,5 \%$ de superioridad. Estos valores representan una estimación del diferencial de selección asociado a usar los mejores materiales genéticos identificados en el ensayo, y permiten estimar la ganancia genética esperada asociada al uso de los mismos ponderándolos por un factor entre 0 y 1 correspondiente a una estimación de la heredabilidad del volumen.

La escasa diferenciación entre procedencias y regiones de procedencia observada en el ensayo Pumillahue coincide con la situación observada en otros ensayos similares de Nothofagus; en prueba de procedencias y progenies de coigüe no se detectó diferencias de desempeño entre zonas de procedencia (Gutiérrez, 2020), así como tampoco en pruebas efectuadas con lenga (Mondino et al., 2010).

Respecto a este fenómeno de escasa variabilidad entre zonas de procedencias y procedencias, Hasbún et al. (2014) establecen que en distribuciones extensas y relativamente continuas existe un elevado flujo génico que reduce la divergencia genética entre las poblaciones. Este efecto ha sido demostrado en estudios de variabilidad isoenzimática de coigüe, donde la variación genética se encuentra principalmente dentro de las poblaciones, mientras que entre poblaciones resulta muy bajo (Donoso et al., 2004).

Adicionalmente, estudios con marcadores moleculares efectuados para otras especies de Nothofagus con extensas áreas de distribución concluyen la existencia de bajos niveles de diferenciación genética poblacional o entre localidades (Hasbún et al., 2014). Posiblemente esta mima situación explica la escasa diferenciación observada en roble.

\section{CONCLUSIÓN}

A los 16 años de edad el ensayo de procedencias y progenies de roble de Huilliemu presenta valores medios de crecimiento y supervivencia equiparables a los señalados en la bibliografía para otras plantaciones de la misma especie. Existe escasa diferenciación de desempeño entre procedencias y regiones de procedencias, siendo más evidente a nivel de progenies. Aun así, el uso de material genético de los mejores orígenes y particularmente de las mejores progenies, involucra una importante superioridad de volumen respecto a la media del ensayo. No obstante, no hay coincidencia entre los mejores materiales y los materiales locales, estos últimos evidencian una superioridad marginal y no se destacan en forma especialmente favorables entre los orígenes y progenies evaluados.

\section{REFERENCIAS}

Alía, R.; García del Barrio, J.; Iglesias, S.; Mancha, J.; de Miguel, J.; Peragón, J.; Pérez, F. y Sánchez del Ron, D., 2009. Regiones de procedencia de especies forestales en España. CIFOR-INIA. Dpto. Sistemas y Recursos Forestales. Madrid, España. 363 p.

Donoso, C.; Premoli, A. y Donoso, P., 2004. Variación en Nothofagus siempreverdes sudamericanos. En: Donoso, C., Premoli, A.; Gallo, L. e Ipinza, R. (editores) Variación Intraespecífica en las especies arbóreas de los bosques templados de Chile y Argentina. Editorial Universitaria. Santiago, Chile. Capítulo 8, pp: 189-214.

Donoso, P.; Maureira, C.; Barría, P y Hernández, E. 1995. Desarrollo inicial de plantaciones de Nothofagus en la provincia de Valdivia. Cuartas Jornadas Forestales Patagónicas. San Martín de los Andes. 18 p.

Donoso, P. y Soto, D. 2010. Plantaciones con especies nativas en el centro-sur de Chile: experiencias, desafíos y oportunidades. Bosque Nativo $N^{\circ} 47$, julio-octubre 2010, pp: 10-17. 
Erikson, V. and Halford, A., 2020. Seed planning, sourcing and procurement. Restoration Ecology 28(s3):s216s224.

García, L.; Droppelmann, F. y Rivero, M., 2013. Morfología y fenología floral de Nothofagus alpina (Nothofagaceae) en un huerto semillero clonal en la región de Los Ríos, Chile. En: Bosque 34(2):221-231.

Gutiérrez, B., 2017. Evaluación de crecimiento y forma de fuste de un ensayo de procedencias y progenies de coihue (Nothofagus dombeyi (Mirb.) Oerst.) de 15 años de edad. Ciencia e Investigación Forestal 23(3): 31-42.

Gutiérrez, B., 2019. Regiones de procedencia: un ordenamiento de fuentes semilleras. Ciencia e Investigación Forestal 25(2):57-73

Gutiérrez, B., 2020. Influencia del origen de las semillas en el desempeño de coigüe (Nothofagus dombeyi (Mirb.) Oerst.) en la costa y precordillera de la región de Los Ríos. Ciencia e Investigación Forestal 26(2):31-43.

Gutierrez, N., 2004. Evaluación de crecimiento y rendimiento volumétricos en ensayos de plantación de Nothofagus obliqua y Nothofagus alpina al aplicar intervenciones silvícolas. Memoria para optar al título de Ingeniero Forestal. Universidad de Chile, Facultad de Ciencias Forestales. Santiago, Chile. 69 p.

Hasbún, R.; Ruiz, E.; Ríos, D.; Fuente, G y Alarcón, D., 2014. Certificación genética del origen de materiales reproductivos de coigüe mediante herramientas moleculares y nichos ecológicos. Informe Final Proyecto FIBNCONAF 068/2012. Universidad de Concepción, Concepción. Octubre 2014. 59 p.

Jones, T. and Monaco, T. A., 2007. Restoration Practitioner's Guide to the Restoration Gene Pool Concept. Ecological Restoration 25:1. March 2007 pp. 12-19.

Landa, J.; Mendizábal, L. del C.; Ramírez, E.; y Méndez, M., 2002. Establecimiento de tres ensayos de procedencia/progenie de Pinus teocote Schl. et Cham. En el estado de Veracruz. Foresta Veracruzana 4(2): 1722.

León, N., 2014. Análisis de ensayos de procedencia-progenie de Dipteryx panamensis (Pittier) Record \& Mell, en la Zona Norte y Sur de Costa Rica. Tesis de Licenciatura en Ingeniería Forestal. Instituto Tecnológico de Costa Rica. Escuela de Ingeniería Forestal. Cártago, Costa Rica. 78 p.

Löewe, V.; Toral, M.; Mery, A.; Camelio, M.; López, C. y Urquieta, E., 1997. Monografía de roble Nothofagus obliqua. Potencialidad de especies y sitios para una diversificación silvícola nacional. INFOR-CONAF-FIA. Santiago, Chile. 108p.

Lowe, A J., 2010. Composite provenancing of seed for restoration: progressing the 'local is best' paradigm for seed sourcing. The State of Australia's Birds 2009: restoring woodland habitats for birds. Compiled by David Paton and James O'Connor. Supplement to Wingspan 20(1) March.

McKay, J. K.; Christian, C. E.; Harrison, S. and Rice, K. J., 2005. How local is local?-a review of practical and conceptual issues in the genetics of restoration. Restoration Ecology 13:432-440.

Mead, R.; Curnow, R. N. and Hasted, A. M., 2002. Statistical methods in agriculture and experimental biology.

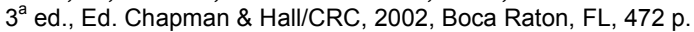

Meneses, M.; Paredes, G.; Núñez, P., 1991. Opciones silviculturales para el manejo y utilización del bosque Siempreverde, Décima Región desde Río Bueno al sur. Informe de Convenio № 184 . Informe Final. Valdivia, Chile. Facultad de Ciencias Forestales, Universidad Austral de Chile. 103 p.

Mijnsbrugge, K. V.; Bischoff, A; Smith, B. M., 2010. A question of origin: where and how to collect seed for ecological restoration. Basic and Applied Ecology 11:300-311.

MMA, 2016. Elaboración de una base digital del clima comunal de Chile: línea base (1980-2010) y proyección al año 2050. Información para de Desarrollo Productivo Ltda. Informe Final. Santiago 16 de junio de 2016.142 p.

Mondino, V.; Tejera, L.; Pastorino, M. y Gallo, L., 2010. Establecimiento en Nothofagus pumilio: efecto de 
plantas nodrizas y procedencias. Poster. Estación Experimental Agroforestal Esquel, Centro Regional Patagonia Sur, INTA Argentina.

Puente, M.; Peñaloza, R.; Donoso, C.; Paredes, R.; Núñez, P.; Morales, R; y Engdahl, O., 1981. Estudio de raleos y otras técnicas para el manejo de renovales de Raulí y Roble. Instalación de ensayos de raleo. Proyecto CONAF/PNUD/FAO-CHI/76/003. Documento de trabajo $\mathrm{N}^{\circ} 41.47 \mathrm{p}$.

Sokal, R. y Rohlf, F. J., 1980. Introducción a la bioestadística. Edición española. Editorial Reverte s.a. Barcelona, España:

Steuer, H., 2008. Evaluación de Raleos en un Renoval de Raulí (Nothofagus alpina Poepp.et Endl.) y Roble (Nothofagus obliqua (Mirb) Oerst) en la Provincia de Malleco, IX Región. Trabajo de titulación para optar al título de Ingeniero Forestal. Universidad Austral de Chile, Facultad de Ciencias Forestales. Valdivia, Chile. 58 p.

Vergara, R.; Ipinza, R.; Donoso, C. y Grosse, H., 1998. Definición de zonas de procedencias de roble (Nothofagus obliqua (Mirb.) Oerst.) y raulí (Nothofagus alpina (Poep. et Endl.) Oerst.). Estado de avance. En: Primer Congreso Latinoamericano IUFRO, "El manejo Sustentable de los Recursos Forestales, Desafío del Siglo XXI". Valdivia, 22 al 28 de noviembre de 1998.

Vita, A., 1977. Crecimiento de algunas especies forestales en el Arboreto del Centro Experimental Frutillar. $X$ Región. Boletín Técnico 47. Facultad de Ciencias Forestales, Universidad de Chile. Santiago. 16 p. 
ANEXO $N^{\circ} 1$

RESULTADOS POR PROGENIE

\begin{tabular}{|c|c|c|c|c|c|c|c|c|}
\hline PROG & $\mathbf{N}^{*}$ & $\begin{array}{l}\text { SUP } \\
\text { [\%] }\end{array}$ & $\mathrm{N}^{+}$ & $\begin{array}{l}\text { VOL } \\
{\left[\mathrm{m}^{3}\right]}\end{array}$ & $\begin{array}{l}\text { ALT } \\
{[\mathrm{m}]}\end{array}$ & $\begin{array}{l}\text { DAP } \\
{[\mathrm{cm}]}\end{array}$ & $\begin{array}{c}R F \\
{[1-4]}\end{array}$ & $\begin{array}{l}\text { BIF } \\
\text { [\%] }\end{array}$ \\
\hline 509 & 5 & $100 a$ & 5 & $0,22 \mathrm{a}$ & $13,96 \mathrm{a}$ & $19,3 \mathrm{a}$ & $2,2 \mathrm{a}$ & $20 a$ \\
\hline 433 & 5 & $100 a$ & 5 & $0,2 a b$ & $14,36 \mathrm{a}$ & $18,14 a b$ & $2,8 a$ & $40 a$ \\
\hline 473 & 5 & $100 \mathrm{a}$ & 5 & $0,18 a b c$ & $13,9 \mathrm{a}$ & $16,98 a b$ & $3,4 \mathrm{a}$ & $40 a$ \\
\hline 461 & 5 & $100 \mathrm{a}$ & 5 & $0,18 a b c$ & $12,82 \mathrm{a}$ & $17,4 a b$ & $2 a$ & $20 a$ \\
\hline 496 & 5 & $80 a b$ & 4 & $0,17 a b c$ & $14,35 \mathrm{a}$ & $15,88 a b c$ & $2,5 \mathrm{a}$ & $25 a$ \\
\hline 448 & 5 & $80 a b$ & 4 & $0,17 a b c$ & $13,5 \mathrm{a}$ & $16,25 \mathrm{abc}$ & $2,5 \mathrm{a}$ & $25 a$ \\
\hline $478[L O C A L]$ & 5 & $100 \mathrm{a}$ & 5 & $0,17 a b c$ & $13,44 \mathrm{a}$ & $16,42 a b c$ & $2,6 \mathrm{a}$ & $20 a$ \\
\hline 438 & 5 & $100 \mathrm{a}$ & 5 & $0,17 a b c$ & $13,38 \mathrm{a}$ & $16,48 a b c$ & $2,2 \mathrm{a}$ & $20 a$ \\
\hline 427 & 5 & $100 \mathrm{a}$ & 5 & $0,17 \mathrm{abc}$ & $13,22 \mathrm{a}$ & $16,26 a b c$ & $2,4 \mathrm{a}$ & $20 a$ \\
\hline 426 & 5 & $100 \mathrm{a}$ & 5 & $0,17 a b c$ & $13,06 \mathrm{a}$ & $16,88 a b$ & $2,6 \mathrm{a}$ & $0 \mathrm{a}$ \\
\hline 553 & 5 & $100 \mathrm{a}$ & 5 & $0,16 a b c$ & $13,88 \mathrm{a}$ & $15,96 a b c$ & $3 a$ & $0 \mathrm{a}$ \\
\hline 445 & 5 & $100 a$ & 5 & $0,16 a b c$ & $13,78 \mathrm{a}$ & $16,04 \mathrm{abc}$ & $2,4 a$ & $0 \mathrm{a}$ \\
\hline 541 & 5 & $100 a$ & 5 & $0,16 \mathrm{abc}$ & $13,56 \mathrm{a}$ & $15,94 a b c$ & $2,6 \mathrm{a}$ & $20 a$ \\
\hline 546 & 5 & $80 a b$ & 4 & $0,16 a b c$ & $13,5 \mathrm{a}$ & $15,73 \mathrm{abc}$ & $2,25 \mathrm{a}$ & $25 \mathrm{a}$ \\
\hline 534 & 10 & $100 \mathrm{a}$ & 10 & $0,16 a b c$ & $13,2 \mathrm{a}$ & $16,2 a b c$ & $2,5 \mathrm{a}$ & $30 a$ \\
\hline 510 & 5 & $80 a b$ & 4 & $0,16 a b c$ & $13,08 \mathrm{a}$ & $16,15 a b c$ & $3 a$ & $0 \mathrm{a}$ \\
\hline 394 & 8 & $100 \mathrm{a}$ & 8 & $0,16 a b c$ & $13,01 \mathrm{a}$ & $16,31 \mathrm{abc}$ & $2,26 \mathrm{a}$ & $10 a$ \\
\hline 475 & 5 & $100 a$ & 5 & $0,16 \mathrm{abc}$ & $13 a$ & $16,52 a b c$ & $2,8 \mathrm{a}$ & $40 a$ \\
\hline 521 & 5 & $100 a$ & 5 & $0,16 a b c$ & $12,6 \mathrm{a}$ & $15,18 \mathrm{abc}$ & $2,4 a$ & $20 a$ \\
\hline 428 & 10 & $100 a$ & 10 & $0,15 a b c$ & $13,34 \mathrm{a}$ & $15,5 \mathrm{abc}$ & $2,6 \mathrm{a}$ & $20 a$ \\
\hline 449 & 10 & $100 a$ & 10 & $0,15 a b c$ & $13,11 \mathrm{a}$ & $15,38 a b c$ & $2,8 \mathrm{a}$ & $30 a$ \\
\hline 430 & 5 & $100 \mathrm{a}$ & 5 & $0,15 a b c$ & $12,9 \mathrm{a}$ & $14,98 a b c$ & $2,8 \mathrm{a}$ & $40 a$ \\
\hline 466 & 5 & $100 \mathrm{a}$ & 5 & $0,15 a b c$ & $12,9 \mathrm{a}$ & $15,14 a b c$ & $2,6 \mathrm{a}$ & $0 \mathrm{a}$ \\
\hline 522 & 5 & $80 a b$ & 4 & $0,15 a b c$ & $12,35 \mathrm{a}$ & $15,78 a b c$ & $2 \mathrm{a}$ & $50 a$ \\
\hline 511 & 5 & $80 a b$ & 4 & $0,15 a b c$ & $12,25 \mathrm{a}$ & $14,75 \mathrm{abc}$ & $2,75 \mathrm{a}$ & $0 \mathrm{a}$ \\
\hline $477[L O C A L]$ & 5 & $80 a b$ & 4 & $0,15 a b c$ & $12,13 \mathrm{a}$ & $16,2 \mathrm{abc}$ & $3,25 \mathrm{a}$ & $25 a$ \\
\hline 450 & 5 & $100 \mathrm{a}$ & 5 & $0,15 a b c$ & $12,1 \mathrm{a}$ & $15,64 a b c$ & $2,2 \mathrm{a}$ & $40 a$ \\
\hline 455 & 5 & $100 a$ & 5 & $0,14 a b c$ & $13,3 \mathrm{a}$ & $14,56 \mathrm{abc}$ & $2,8 a$ & $20 a$ \\
\hline 474 & 5 & $80 a b$ & 4 & $0,14 a b c$ & $13,05 \mathrm{a}$ & $13,9 a b c$ & $2,75 a$ & $0 \mathrm{a}$ \\
\hline 458 & 5 & $100 a$ & 5 & $0,14 a b c$ & $12,86 \mathrm{a}$ & $14,74 \mathrm{abc}$ & $2,6 \mathrm{a}$ & $0 \mathrm{a}$ \\
\hline 517 & 10 & $90 \mathrm{a}$ & 9 & $0,14 a b c$ & $12,85 \mathrm{a}$ & $14,68 a b c$ & $2,91 \mathrm{a}$ & $20 a$ \\
\hline 528 & 5 & $80 a b$ & 4 & $0,14 a b c$ & $12,58 \mathrm{a}$ & $15,05 a b c$ & $2,5 a$ & $0 \mathrm{a}$ \\
\hline 439 & 8 & $100 a$ & 8 & $0,14 a b c$ & $12,38 \mathrm{a}$ & $14,9 \mathrm{abc}$ & $1,92 \mathrm{a}$ & $10 a$ \\
\hline 456 & 5 & $100 \mathrm{a}$ & 5 & $0,14 a b c$ & $12,28 \mathrm{a}$ & $14,98 \mathrm{abc}$ & $2,6 \mathrm{a}$ & $20 a$ \\
\hline 495 & 5 & $100 a$ & 5 & $0,14 a b c$ & $12,24 \mathrm{a}$ & $14,76 \mathrm{abc}$ & $2,8 \mathrm{a}$ & $0 \mathrm{a}$ \\
\hline 378 & 5 & $100 a$ & 5 & $0,14 \mathrm{abc}$ & $12,18 \mathrm{a}$ & $14,4 \mathrm{abc}$ & $3 a$ & $0 \mathrm{a}$ \\
\hline $484[L O C A L]$ & 5 & $80 a b$ & 4 & $0,14 a b c$ & $12,18 \mathrm{a}$ & $15,25 a b c$ & $2,75 a$ & $50 a$ \\
\hline 482 [LOCAL] & 5 & $100 a$ & 5 & $0,14 a b c$ & $12,16 \mathrm{a}$ & $14,98 \mathrm{abc}$ & $2,4 a$ & $20 a$ \\
\hline 424 & 5 & $80 a b$ & 4 & $0,14 a b c$ & $11,95 \mathrm{a}$ & $15,53 a b c$ & $2,75 a$ & $25 a$ \\
\hline 443 & 5 & $100 a$ & 5 & $0,14 a b c$ & $11,92 \mathrm{a}$ & $14,52 a b c$ & $2,8 \mathrm{a}$ & $20 a$ \\
\hline
\end{tabular}




\begin{tabular}{|c|c|c|c|c|c|c|c|c|}
\hline 485 [LOCAL] & 5 & $100 \mathrm{a}$ & 5 & $0,14 a b c$ & $11,62 \mathrm{a}$ & $14,46 \mathrm{abc}$ & $3 a$ & $40 a$ \\
\hline 442 & 5 & $100 \mathrm{a}$ & 5 & $0,14 a b c$ & $11,4 \mathrm{a}$ & $14,38 \mathrm{abc}$ & $2 \mathrm{a}$ & $40 a$ \\
\hline 391 & 5 & $100 a$ & 5 & $0,14 a b c$ & $11,38 \mathrm{a}$ & $14,2 \mathrm{abc}$ & $2,6 \mathrm{a}$ & $20 \mathrm{a}$ \\
\hline 526 & 5 & $100 \mathrm{a}$ & 5 & $0,13 a b c$ & $13,2 \mathrm{a}$ & $13,58 \mathrm{abc}$ & $3,2 \mathrm{a}$ & $0 \mathrm{a}$ \\
\hline 451 & 5 & $80 a b$ & 4 & $0,13 a b c$ & $12,85 \mathrm{a}$ & $14,18 a b c$ & $3 a$ & $0 \mathrm{a}$ \\
\hline 471 & 5 & $100 \mathrm{a}$ & 5 & $0,13 a b c$ & $12,62 \mathrm{a}$ & $13,7 \mathrm{abc}$ & $3,2 \mathrm{a}$ & $0 \mathrm{a}$ \\
\hline 547 & 5 & $100 \mathrm{a}$ & 5 & $0,13 a b c$ & $12,62 \mathrm{a}$ & $13,72 \mathrm{abc}$ & $2,6 \mathrm{a}$ & $20 a$ \\
\hline 552 & 5 & $100 \mathrm{a}$ & 5 & 0,13 abc & $12,58 \mathrm{a}$ & $14,56 \mathrm{abc}$ & $3 a$ & $20 a$ \\
\hline 454 & 5 & $100 \mathrm{a}$ & 5 & $0,13 a b c$ & $12,28 \mathrm{a}$ & $13,98 a b c$ & $2 a$ & $0 \mathrm{a}$ \\
\hline 440 & 5 & $100 \mathrm{a}$ & 5 & $0,13 a b c$ & $12,14 \mathrm{a}$ & $13,58 \mathrm{abc}$ & $2,4 a$ & $0 \mathrm{a}$ \\
\hline 548 & 5 & $100 \mathrm{a}$ & 5 & $0,13 a b c$ & $12,12 \mathrm{a}$ & $14,02 \mathrm{abc}$ & $2,6 a$ & $40 \mathrm{a}$ \\
\hline 457 & 5 & $80 a b$ & 4 & $0,13 a b c$ & $11,98 \mathrm{a}$ & $14,08 \mathrm{abc}$ & $2,75 \mathrm{a}$ & $0 \mathrm{a}$ \\
\hline 398 & 6 & $100 \mathrm{a}$ & 6 & $0,13 a b c$ & $11,93 \mathrm{a}$ & $13,88 \mathrm{abc}$ & $3,02 \mathrm{a}$ & $30 \mathrm{a}$ \\
\hline 529 & 10 & $90 \mathrm{a}$ & 9 & $0,13 a b c$ & $11,72 \mathrm{a}$ & $13,77 \mathrm{abc}$ & $1,76 \mathrm{a}$ & $10 a$ \\
\hline 399 & 5 & $100 \mathrm{a}$ & 5 & 0,13 abc & $11,4 \mathrm{a}$ & $12,8 a b c$ & $2,8 \mathrm{a}$ & $0 \mathrm{a}$ \\
\hline 434 & 5 & $100 \mathrm{a}$ & 5 & $0,13 a b c$ & $11,08 \mathrm{a}$ & $13,94 a b c$ & $2 a$ & $20 a$ \\
\hline 551 & 5 & $100 \mathrm{a}$ & 5 & $0,12 a b c$ & $12,88 \mathrm{a}$ & $12,88 \mathrm{abc}$ & $2,6 \mathrm{a}$ & $60 a$ \\
\hline 392 & 5 & $100 \mathrm{a}$ & 5 & $0,12 a b c$ & $12,62 \mathrm{a}$ & $12,52 \mathrm{abc}$ & $2,6 \mathrm{a}$ & $0 \mathrm{a}$ \\
\hline 550 & 5 & $100 \mathrm{a}$ & 5 & $0,12 a b c$ & $12,52 \mathrm{a}$ & $13,26 a b c$ & $2,2 \mathrm{a}$ & $0 \mathrm{a}$ \\
\hline 505 & 5 & $80 a b$ & 4 & $0,12 a b c$ & $12,4 \mathrm{a}$ & $12,73 a b c$ & $3 a$ & $0 \mathrm{a}$ \\
\hline 504 & 5 & $100 \mathrm{a}$ & 5 & $0,12 a b c$ & $12,2 \mathrm{a}$ & $12,62 \mathrm{abc}$ & $2,8 \mathrm{a}$ & $0 \mathrm{a}$ \\
\hline 532 & 10 & $100 \mathrm{a}$ & 10 & $0,12 a b c$ & $12,14 \mathrm{a}$ & $12,87 \mathrm{abc}$ & $2,7 \mathrm{a}$ & $0 \mathrm{a}$ \\
\hline 479 [LOCAL] & 5 & $100 \mathrm{a}$ & 5 & $0,12 a b c$ & $12,08 \mathrm{a}$ & $12,82 \mathrm{abc}$ & $2,8 \mathrm{a}$ & $20 a$ \\
\hline 535 & 5 & $80 a b$ & 4 & $0,12 a b c$ & $11,95 \mathrm{a}$ & $12,83 a b c$ & $2,75 \mathrm{a}$ & $0 \mathrm{a}$ \\
\hline TESTIGO & 25 & $92 \mathrm{a}$ & 23 & 0,12 abc & $11,92 \mathrm{a}$ & $13,46 a b c$ & $2,6 a$ & $13 \mathrm{a}$ \\
\hline 401 & 5 & $80 a b$ & 4 & 0,12 abc & $11,78 \mathrm{a}$ & $12,98 \mathrm{abc}$ & $3 a$ & $0 \mathrm{a}$ \\
\hline 400 & 10 & $100 \mathrm{a}$ & 10 & $0,12 a b c$ & $11,6 \mathrm{a}$ & $13,11 \mathrm{abc}$ & $2,6 a$ & $10 a$ \\
\hline 370 & 5 & $100 \mathrm{a}$ & 5 & $0,12 a b c$ & $11,58 \mathrm{a}$ & $13,96 \mathrm{abc}$ & $2,2 a$ & $20 a$ \\
\hline 435 & 5 & $100 \mathrm{a}$ & 5 & $0,12 a b c$ & $11,56 \mathrm{a}$ & $13,7 a b c$ & $2,2 \mathrm{a}$ & $0 \mathrm{a}$ \\
\hline 382 & 10 & $70 a b$ & 7 & $0,12 a b c$ & $11,34 a$ & $12,38 a b c$ & $2,85 \mathrm{a}$ & $0 \mathrm{a}$ \\
\hline 476 [LOCAL] & 10 & $90 \mathrm{a}$ & 9 & 0,12 abc & $11,19 \mathrm{a}$ & $13,69 \mathrm{abc}$ & $2,43 a$ & $0 \mathrm{a}$ \\
\hline 515 & 5 & $100 a$ & 5 & $0,11 \mathrm{abc}$ & $12,5 \mathrm{a}$ & $12,74 \mathrm{abc}$ & $1,8 \mathrm{a}$ & $0 \mathrm{a}$ \\
\hline 533 & 5 & $80 \mathrm{ab}$ & 4 & $0,11 \mathrm{abc}$ & $12,28 \mathrm{a}$ & $12,53 \mathrm{abc}$ & $2,5 \mathrm{a}$ & $0 \mathrm{a}$ \\
\hline 531 & 10 & $70 a b$ & 7 & $0,11 \mathrm{abc}$ & $11,82 \mathrm{a}$ & $12,79 a b c$ & $2,32 \mathrm{a}$ & $10 a$ \\
\hline 524 & 5 & $100 \mathrm{a}$ & 5 & $0,11 b c$ & $11,66 a$ & $11,68 \mathrm{abc}$ & $2,6 a$ & $0 \mathrm{a}$ \\
\hline 403 & 5 & $100 \mathrm{a}$ & 5 & $0,11 b c$ & $11,46 \mathrm{a}$ & $12,42 a b c$ & $2,8 \mathrm{a}$ & $20 a$ \\
\hline 390 & 5 & $100 \mathrm{a}$ & 5 & $0,11 b c$ & $10,36 \mathrm{a}$ & $11,74 a b c$ & $2,2 \mathrm{a}$ & $0 \mathrm{a}$ \\
\hline 259 & 5 & $80 a b$ & 4 & $0,1 \mathrm{bc}$ & $12,45 \mathrm{a}$ & $11,1 \mathrm{bc}$ & $2,25 \mathrm{a}$ & $25 a$ \\
\hline 525 & 10 & $100 \mathrm{a}$ & 10 & $0,1 \mathrm{bc}$ & $11,68 \mathrm{a}$ & $11,85 a b c$ & $3 a$ & $0 \mathrm{a}$ \\
\hline 537 & 5 & $100 \mathrm{a}$ & 5 & $0,1 \mathrm{bc}$ & $11,64 a$ & $11,98 a b c$ & $2,6 a$ & $20 a$ \\
\hline 437 & 5 & $100 \mathrm{a}$ & 5 & $0,1 \mathrm{bc}$ & $11,28 \mathrm{a}$ & 10,96 bc & $2,6 a$ & $40 a$ \\
\hline 393 & 5 & $80 a b$ & 4 & $0,1 \mathrm{bc}$ & $11,2 \mathrm{a}$ & $10,25 \mathrm{bc}$ & $2,25 a$ & $0 \mathrm{a}$ \\
\hline 549 & 5 & $80 \mathrm{ab}$ & 4 & $0,1 \mathrm{bc}$ & $10,98 \mathrm{a}$ & $11,68 \mathrm{abc}$ & $2 \mathrm{a}$ & $0 \mathrm{a}$ \\
\hline 367 & 5 & $80 a b$ & 4 & $0,08 \mathrm{c}$ & $10,98 \mathrm{a}$ & $8,75 \mathrm{c}$ & $2,25 a$ & $0 \mathrm{a}$ \\
\hline 254 & 1 & $100 \mathrm{a}$ & \multicolumn{6}{|c|}{ No evaluada } \\
\hline 441 & 2 & $100 \mathrm{a}$ & \multicolumn{6}{|c|}{ No evaluada } \\
\hline 318 & 5 & $60 a b$ & \multicolumn{6}{|c|}{ No evaluada } \\
\hline 360 & 5 & $60 \mathrm{ab}$ & \multicolumn{6}{|c|}{ No evaluada } \\
\hline 373 & 5 & $60 a b$ & \multicolumn{6}{|c|}{ No evaluada } \\
\hline 381 & 5 & $60 a b$ & \multicolumn{6}{|c|}{ No evaluada } \\
\hline 383 & 5 & $60 \mathrm{ab}$ & \multicolumn{6}{|c|}{ No evaluada } \\
\hline 386 & 5 & $60 a b$ & \multicolumn{6}{|c|}{ No evaluada } \\
\hline 380 & 5 & $20 \mathrm{~b}$ & \multicolumn{6}{|c|}{ No evaluada } \\
\hline PROMEDIO & & 90,5 & & 0,14 & 12,37 & 14,25 & 2,57 & 14,95 \\
\hline DMS & & 67,552 & & 0,113 & 4,42 & 8,117 & 1,819 & 94,713 \\
\hline
\end{tabular}

Letras distintas en la misma columna indican diferencias estadísticamente significativas entre medias (Tuckey alfa $=0,05$ )

${ }^{*} \mathrm{~N}$ : Total de plantas iniciales en el ensayo

$+n$ : plantas evaluadas (aquellas de progenies con 4 o más plantas vivas) 
